\section{$\underset{\substack{\text { hommes } \\ \text { \& migrations }}}{ }$}

\section{Hommes \& migrations}

Revue française de référence sur les dynamiques

migratoires

$1330 \mid 2020$

1973, l'année intense

\title{
Pierre Puchot (dir.), Islam et politique
}

Perrin, Paris, 2019, 448 pages, $10 €$.

Jean-Baptiste Meyer

\section{OpenEdition}

1 Journals

Édition électronique

URL : https://journals.openedition.org/hommesmigrations/11718

DOI : 10.4000/hommesmigrations. 11718

ISSN : 2262-3353

Éditeur

Musée national de l'histoire de l'immigration

Édition imprimée

Date de publication : 17 juillet 2020

Pagination : 244

ISBN : 978-2-919040-51-3

ISSN : 1142-852X

Référence électronique

Jean-Baptiste Meyer, «Pierre Puchot (dir.), Islam et politique », Hommes \& migrations [En ligne], 1330 |

2020, mis en ligne le 01 juillet 2020, consulté le 05 janvier 2023. URL : http://journals.openedition.org/ hommesmigrations/11718; DOI : https://doi.org/10.4000/hommesmigrations.11718 


\section{Islam et politique}

Pierre Puchot (dir.), Paris, Perrin, 2019, 448 p., $10 €$.

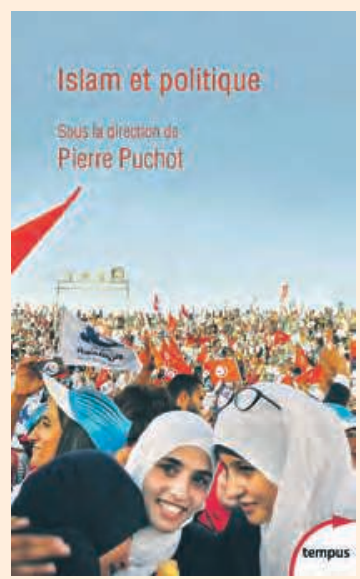

Cet ouvrage collectif compare l'émergence des mouvements islamistes dans 13 pays de la région MENA (Moyen-Orient et Afrique du Nord): l'Égypte, l'Arabie Saoudite, le Levant, le Liban, partiellement l'Irak et la Syrie, le Qatar, la Tunisie, le Maroc, l'Algérie, la Turquie, Gaza, le Yemen ainsi que les engagements extérieurs des États-Unis. Chaque pays fait l'objet d'une analyse essentiellement politique et historique de l'émergence et des vicissitudes des mouvements islamistes. Les descriptions convergent sur la période récente des «Printemps arabes» et se centrent sur des mouvements qui gravitent autour du pouvoir et parfois l'investissent. Elles font, pour la plupart, référence au mouvement des Frères musulmans de Hassan al-Banna durant les années 1930 en Égypte, qu'elles identifient comme origine ou inspiration de l'islam politique contemporain.

Dès l'introduction, l'ouvrage souligne clairement la grande diversité des expressions de l'islam sunnite politique. On est loin de l'image monolithique, antioccidentale et radicale telle qu'elle est perçue notamment en Europe. Les trajectoires multiples prises par les mouvements dans les différents pays attestent d'un travail considérable d'adaptation à des circonstances locales variables. La confrontation avec les pouvoirs autoritaires, dictateurs nationalistes (Algérie, Égypte, Syrie Tunisie, Yémen) ou monarchies (Arabie Saoudite, Jordanie, Maroc, Qatar) oblige tantôt à la clandestinité, voire au conflit, tantôt au compromis, voire aux compromissions.

Ces mouvements islamistes jouent un jeu politique légaliste et s'insèrent dans les processus électoraux pour la conquête du pouvoir. Ils fondent des partis politiques: PJD (Parti de la justice et du développement) au Maroc, Ennahdha («renaissance») en Tunisie, Jamaa-al-islamiya au Liban, Al-Islah au Yemen, le MSP (Mouvement de la société pour la paix) en Algérie. Ils possèdent généralement un volet associatif et défendent des options sociétales, culturelles, religieuses (la Gamaa - «communauté» - en Égypte pour les frères musulmans), tandis que les politiques ont les mains libres pour opérer de façon pragmatique. Ils ont rarement été à l'origine directement des protestations du tournant des années 2010 mais s'y sont ralliés via leurs jeunes militants. Leur capacité souvent inégalée d'encadrement de la société civile leur a permis de revendiquer et de s'approcher, et parfois de gagner le pouvoir, au moins pour un temps.

La circulation des hommes et des idées est un trait commun à plusieurs de ces expériences d'islam politique. Elle est souvent liée aux répressions politiques dont ses porteurs sont l'objet. Celles du régime nassérien, en particulier, ont largement contribué à des exils propagateurs des idées des fils spirituels d'Hassan al-Banna. Les hommes de savoir de l'islam ont nourri les établissements scolaires et universitaires d'Arabie Saoudite et du Qatar, dont ils ont même forgé les cadres du jeune État. Leurs idées se sont diffusées aussi par leurs étudiants et élèves (Liban, Syrie, Yémen). En Tunisie, l'expérience diasporique du conseil exécutif, qui changeait sans cesse de lieu en Europe a enrichi le patrimoine expérientiel d'Ennahdha. Enfin, l'avènement du gouvernement de Mohamed Morsi a poussé les initiatives voisines (Hamas, Jamaa al-islamiya, Al-Islah) puis les a entraînées dans leur chute. On perçoit à quel point cette interdépendance liée à la circulation articule l'islam politique au-delà de sa diversité.

En définitive, l'ouvrage permet de comprendre l'extrême complexité des relations politiques dans ces États où interviennent les islamistes. De la sorte sont explicités leurs succès relatifs, mais aussi leurs difficultés ainsi que leur résilience. En revanche, ce livre occulte singulièrement les contenus spirituels, les pensées religieuses et leur efficacité sociale, leur puissance de mobilisation ou de persuasion. Si les aspects politiques deviennent compréhensibles - dans la mécanique des relations, des personnes et des partis/ mouvements - les forces sociales mues par la conviction des idées et la transmission des croyances et des pratiques demeurent malheureusement dans l'ombre. Pour quitter cette vision externaliste et intégrer complètement le politique et le religieux, il aurait fallu entrer dans le cœur de la (des) pensée(s) islamique(s) et de leur socialisation. C'est à ce prix seulement que le projet scientifique de l'ouvrage dépasser l'eurocentrisme et la simplification - pourrait véritablement être atteint.

Jean-Baptiste Meyer 